\title{
MODEL FOR REVELATION OF UNFRIENDLY INFORMATION IMPACTS IN MASS-MEDIA WHICH ARE DIRECTED ON CHANGE OF PUBLIC OPINION
}

\author{
Viktor BOCHARNIKOV1', Sergey SVESHNIKOV², Stepan VOZNYAK², Vladimir \\ YUZEFOVICH ${ }^{4}$ \\ ${ }^{1}$ Consulting Group INEX-FT, 03011 Desjatinnaja str 13a, 2, Kiev, Ukraine, bocharnikovvp@yandex.ru \\ ${ }^{2}$ Consulting Group INEX-FT, 03011 Desjatinnaja str 13a, 2, Kiev, Ukraine, sveshnikovsv@yandex.ru \\ ${ }^{3}$ Consulting Group INEX-FT, 03011 Desjatinnaja str 13a, 2, Kiev, Ukraine, step-voz@mail.ru \\ ${ }^{4}$ Consulting Group INEX-FT, 03011 Desjatinnaja str 13a, 2, Kiev, Ukraine, uzefv@inet.ua
}

\begin{abstract}
In this article we propose the mathematical model for revelation of deliberate unfriendly information impacts which are fulfilled by means of specially prepared information messages (news, reviews and others) in mass-media. The model calculates the quantitative measure for fact determination of purposeful information impact and evaluation of potential damage to interests of state (party, corporation) from impact fulfilment. The model use the following data: intensity and direction of information streams (publication frequency and themes of news), structure of important state and public problems, structure of social groups of a society, priorities of these social groups, mass-media popularity in social groups, priorities of a state policy. The model is the semantic network in which the relations between concepts we formalize by use of fuzzy measures by Sugeno. We have used this model for revelation of information impacts on public opinion of Russian-speaking national minority of Crimea (Ukraine) during $01.2002-02.2005$ (final stage of presidential elections). The model also can has important implications for evaluation of election cleanness, for neutralization of dirty voting technologies, for facts determination of unfair competition, when corporations involve a public opinion into own competitive activity.
\end{abstract}

Keywords: public opinion; information impact; fuzzy measures; mathematical model

\section{INTRODUCTION}

We consider a revelation problem of unfriendly information impacts on public opinion in context of practical topicality and availability of theoretical decisions.

Practical topicality. The states, political parties, transnational corporations use mass-media as a portal for information interchange with a society. The partial purposes of this exchange are: society informing, an explanation of the ideas and decisions, mobilization of a society at the decision of the important state and public problems. A final purpose of information exchange is creation of public support. In other words, influential players (the governments, parties, corporations) use mass-media for change or consolidation of public opinion in the own interests. We insist what these players use mass-media only in the own interests. 
MANAGEMENT RESEARCH AND PRACTICE Vol. 2 Issue 1 (2010) p: 21-38

However, interests of influential players not always coincide. Interests' discrepancy especially often arises in the international relations between the states. In this case, players (deliberately or accidentally) use massmedia against interests of other players as follows. In mass-media the player initiates the publications series of specially prepared news, reviews, and interviews of authoritative experts and politicians. These publications can infringe on interests of other players. We have named these publications as information messages. In case of accidental use of mass-media, the information messages are not purposeful. They do not create complete system of influences and therefore cannot make essential damage to interests of other players. If the player uses mass-media deliberately, he initiates a purposeful stream of information messages. Their contents and publication time depend on the player purpose, features of information space and public opinion.

Therefore here arises a problem of revelation (identification) of deliberate unfriendly information impacts on public opinion and also a problem of evaluation of their potential damage to interests of other players (impact objects). Impact objects should solve this problem constantly and in real time as players prepare deliberate information impacts secretly and begin their suddenly. For impact neutralization the impact objects haven't sufficient time.

In practice of the international relations we observe examples multitude when the states use mass-media against interests of other states. During August - September, 2008 the European mass-media has published multitude of news in which they represented Russia by aggressor in war with Georgia. Such news has caused essential damage to image of Russia in the Europe: NATO has suspended the relations with Russia. However, as it has been recognized, an aggressor in this war was Georgia. In January, 2009 we have observed the real information war between Russia and Ukraine concerning the deliveries suspension of the Russian gas to the Europe. Russia actively has supported own interests not only in information space of the Europe, but also Ukraine as Russia broadcasts a part of own mass-media into Ukraine. Ukraine was not ready to neutralization of this impact. As a result the majority of the interrogated citizens of Ukraine have declared that Russia has won gas war (Survey by the public opinion foundation, 2008). Here we have mentioned examples of information impacts which have been fulfilled by the states. Corporations and political parties also can fulfill an information impacts. We consider a classical example of deliberate long-term information impact in the end of this article.

Thus, in everyday life we often observe information impacts. The problem of timely revelation of unfriendly information impacts is topical from the view-point of practice. For the state the decision of this problem is a necessary condition of information space control and maintenance of information safety.

Theoretical decisions. The multitude of modern sociological researches analyse a public opinion and its features. So, Gartner (2008) and Berinsky (2006) investigate influence of casualties on public support of war. 
Asfaw (2006) investigates the dependence of adaptation efficiency of information and communication technologies from socio-personal factors on the basis of public-opinion poll. Ladd (2007) investigates the dependence of presidential approval in society from defence policy predispositions and prior political awareness.

Researchers also consider the problem of public opinion formation (change) for creating public support of government or corporations policy (actions). Lindley (2004) analyzes information UN operation in Cambodia before elections. Jajko (2002) considers problems of information operations of U.S. Department of Defense. Lonsdale (2004) investigates the fundamental nature of information warfare and its implications for geopolitics. Koster et al. (2008) investigate a role of information in formation of public opinion concerning opposition support and creation of revolutionary situations. Lohmann (1993), Schofield and Cataife (2006) investigate partial questions of influence of expensive political actions on elections results. Cohen, Tsfati and Sheafer (2008) investigate the role of mass-media in activity stimulation of politicians. Maier (2008) considers influence of mass-media on citizens' attitude towards EU enlargement.

As a whole, the results analysis of well-known researches has shown:

1. The researches not consider the revelation problem of information impacts and of quantitative damage evaluation from them.

2. The researches conclusions have qualitative character and do not give quantitative data for decision-making.

3. The mathematical decisions for quantitative measurement of information impacts intensity and of today damage from them are absent in researches.

Thus, the revelation problem of information impacts and damage evaluation from them is typical from viewpoint of both practice, and theory. Therefore the purpose of this research is creation and testing of mathematical model which allows quantitatively evaluating:

- a fact of fulfilment of deliberate information impacts;

- a potential damage from information impacts.

\section{DEFINITIONS}

Information impact. We consider the information impact as aggregate of information actions of politicaleconomical force which they coordinate along the purpose, place and tools, time and objects of impact. The political-economical force fulfils the information impact in the form of consecution of information messages in mass-media. 
Political-economical forces. We consider the states, the states coalitions, transnational corporations, political parties and other influential players as the political-economical forces. Every political-economical force have own interests. We consider the interests of political-economical force as the aggregate of views (or as the preferences system) concerning decision variants of important state and public problems. By means of information messages in mass-media the political-economical force convinces society in effectiveness of problem decision variant which corresponds to it preferences. If the preferences system of this political-economical force contradicts the preferences system of other political-economical force, we name the information impacts by unfriendly impact. In article we consider only unfriendly information impacts. We name the political-economical force which fulfils the impact by impact-initiator. We also name the contrary political-economical force by impact-addressee.

Objects of information impact. The objects of information impact are social groups which can be differentiated along ethnic, racial, professional and other attributes. The main condition for differentiation of social groups is clear-cut distinction of preferences concerning the decision variants of important state and public problems. We consider a public opinion as aggregate of the preferences of all social groups.

Purposes of information impact. The main purpose of information impact is change of preferences system (views, priorities) of impact objects for achievement of maximal coincidence with preferences system of impact-initiator. The partial purposes of information impact can be:

- public support of war;

- actualization of new socially important problems;

- creation of external enemy image for deviation of voter attention from domestic economic problems;

- intimidation of politicians for motivation to compromises.

Place and tools of information impact. The impact-initiator can fulfil the information impact in own information space or in information space of impact-addressee. The tools of information impact are massmedia. The impact-initiator prepares and publishes the information messages in popular mass-media or stimulates their publication. The impact-initiator determines the messages content according to the own decision variants of important problems. In information messages mass-media propagandize the preferable variants (from view-point of impact-initiator) or criticize other variants.

The time characteristics of information impact. The impact-initiator determines the time-moment for information impact according to own purposes and with taking into account of sluggishness of public opinion. The information impact can be fulfilled as several consecutive impacts with different intensity. 


\section{LOGICAL MODEL}

The basic model idea is comparison of preferences concerning the decision variants of the important state and public problems: preferences in information messages of mass-media, preferences of social groups, preferences of impact-addressee.

Revelation of information impact. The impact-initiator publishes information messages in mass-media. These information messages evaluate some of the problems decision variants positively or negatively. However the impact-addressee has other views concerning the problems decision variants. Therefore the contradiction appears between the messages content and preferences of impact-addressee. The familiarization of social groups with messages content depends from popularity of mass-media in these social groups. If information messages are published in unpopular mass-media, then information impact does not influence public opinion. If information messages are published in mass-media which are popular only in one social group, then information impact is directed only at this social group. If information messages are published in all popular mass-media, then information impact is large-scale and is directed at all social groups.

Therefore, attributes for revelation of information impact are:

- contradictions level of the information messages content with the preferences system of the impactaddressee;

- familiarization level of social groups with the content of information messages.

The possibility of information impact is high, if both of the specified levels are maximal. The model calculates the possibility of information impact by means of logic operation "And" for the specified attributes.

Evaluation of potential damage from information impact (Evaluation of stimulated tension between society and impact-addressee). We consider the damage to impact-addressee from information impact as contradictions level (or relations tension) between preferences of social groups and the impact-addressee. Therefore we suppose that the potential damage can be evaluated by relations tension between social groups and the impact-addressee.

Contradictions arise as result of information impact. The high contradictions level conforms to the high potential damage to the interests of the impact-addressee. In this case public support of the impactaddressee is minimal. The high contradictions level arises, when the content of information messages in mass-media coincides with preferences of social groups and does not coincide with preferences of the impact-addressee. 
Therefore, two attribute is important for evaluation of relations tension:

- fact of information impact;

- coincidence level of preferences in information messages with the preferences of social groups.

The model calculates the relations tension also by means of logic operation "And" for the specified attributes. Thus, the model is based on two logic dependences:

\begin{tabular}{|c|c|c|c|c|}
\hline $\begin{array}{l}\text { Possibility of } \\
\text { information impact }\end{array}$ & $=$ & $\begin{array}{l}\text { Contradictions level of } \\
\text { content of information } \\
\text { messages in mass-media with } \\
\text { the preferences system of } \\
\text { impact-addressee }\end{array}$ & "AND" & $\begin{array}{l}\text { Familiarization level of social } \\
\text { groups with the content of } \\
\text { information messages }\end{array}$ \\
\hline Relations tension & $=$ & $\begin{array}{l}\text { Possibility of information } \\
\text { impact }\end{array}$ & "AND" & $\begin{array}{c}\text { Coincidence level of } \\
\text { preferences in information } \\
\text { messages with the preferences } \\
\text { of social groups }\end{array}$ \\
\hline
\end{tabular}

FIGURE 1 - LOGIC DEPENDENCES.

Dynamic aspect. The time of information messages influence also is important for revelation of the information impact. The information impact should influence public opinion constantly and continuously for efficiency increase. The impact-initiator should regularly publish information messages because topicality time of every separate message is limited. As shows by experience the message topicality time averages 3-4 days. After the publication the information message causes discussion (public resonance) and then gradually loses the own topicality. Social groups gradually forget this message. Figure 2 demonstrates influence of information messages stream. The information messages are represented as trapezes (with gradual increase and decrease of message influence force). The trapeze height corresponds to popularity of mass-media in social group.

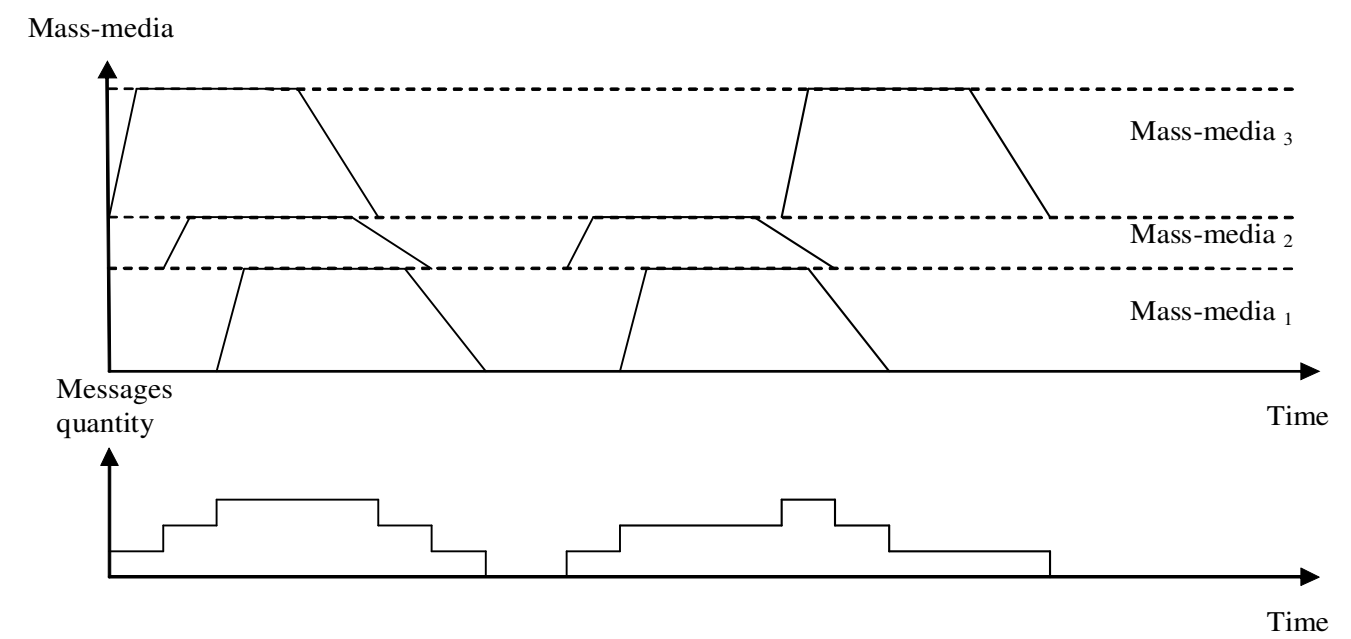




\section{Structure of model}

Figure 3 represents the structure of model with explanations of partial estimations.

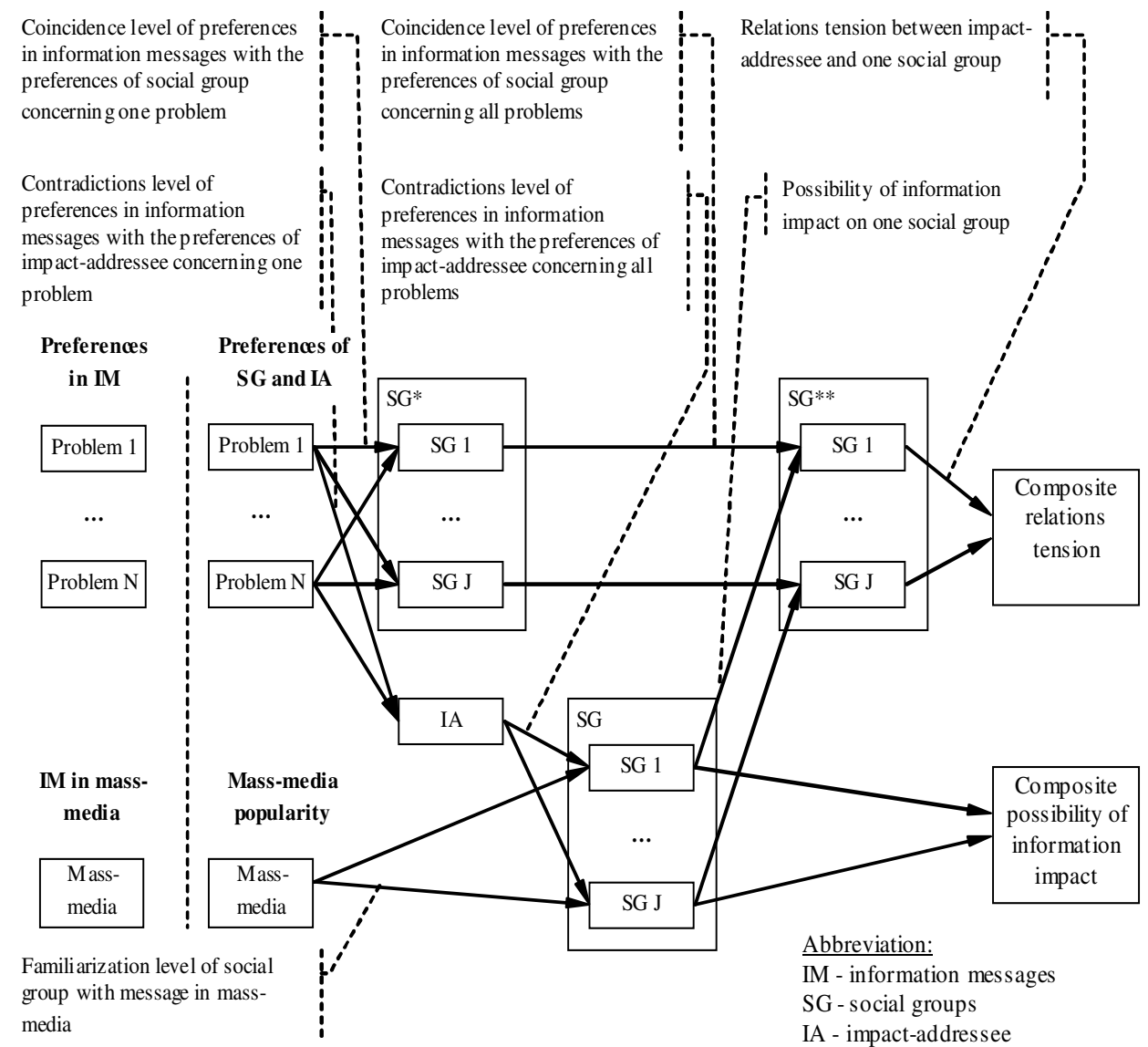

FIGURE 3 - THE MODEL STRUCTURE.

The model is the set of interrelated elementary concepts which denote the preferences (of social groups, the impact-addressee and preferences in information messages) concerning important state and public problems. The quadrangles - graph tops denote the concepts of model. The top in arrow ending is the consideration context (view-point) for top in the arrow beginning. In each top the model calculates several estimations according to contexts number of this top. The arrow direction shows calculations consecution.

An example. To entrance of the top "SG 1" the model gives the coincidence levels of preferences in information message with the preferences of social group concerning each problem. In exit of top "SG 1" the model calculates the generalized coincidence level along all problems. The model calculates the generalized estimations by means of fuzzy integral Sugeno (1972). In each top the user assigns the fuzzy measures according to contexts number of this top. The model formalizes the entrance estimations as membership of fuzzy set $X$ and calculates the generalized estimation for one context as integration result of membership $h(x): X \rightarrow[0,1]$ along contextual fuzzy measure $g(\cdot): 2^{X} \rightarrow[0,1]:$ 
$L=\int_{x} h(x) \circ g(x)$

In each top the model fulfils the integration of entrance estimations some times (according to contexts number). The generalized estimations in the tops (arrows beginning) are the entrance estimations for integration in the next top (arrow ending).

The model fulfils the calculations step by step.

Step 1. The analysis of information messages in mass-media.

The model fulfils the calculations in the tops group "Problem 1 - Problem N" and in the top "Mass-media". On this step the model calculates the following estimations:

- contradictions levels of preferences in information messages with preferences of the impactaddressee concerning each problem;

- coincidence levels of preferences in information messages with preferences of social groups concerning each problem;

- familiarization level of social groups with information messages in mass-media.

\section{Calculation of contradictions levels of preferences.}

The model fulfils the calculation in the tops group "Problem 1 - Problem N" for context of top "IA". In each top the user formalizes the preferences of the impact-addressee. These preferences reflect the views of the impact-addressee concerning decision variants of important state and public problems. Lists of problems and possible variants of their decision can be determined on the basis of themes analysis of current messages in mass-media. Depending on the problem formulation the model uses two assignment variants of preferences.

Assignment variant 1. The model uses this variant for "homogeneous" problems, for example for the problem "The integration of Ukraine into EU". In this problem the decision variants can be easily formulated. In each top out the group "Problem 1 - Problem N" the user assigns the gradations set which correspond to variants of problem decision. On these variants the user assigns the fuzzy measure which characterizes unacceptability (undesirability) of each decision variant from view-point of the impact-addressee. Figure 4 at the left demonstrates this assignment variant. On the set of variants the user also assigns the membership which characterizes the preferences in information messages. The model integrates these preferences along unacceptability measure of decision variants for impact-addressee. As integration result the model calculates the contradictions level of preferences. 


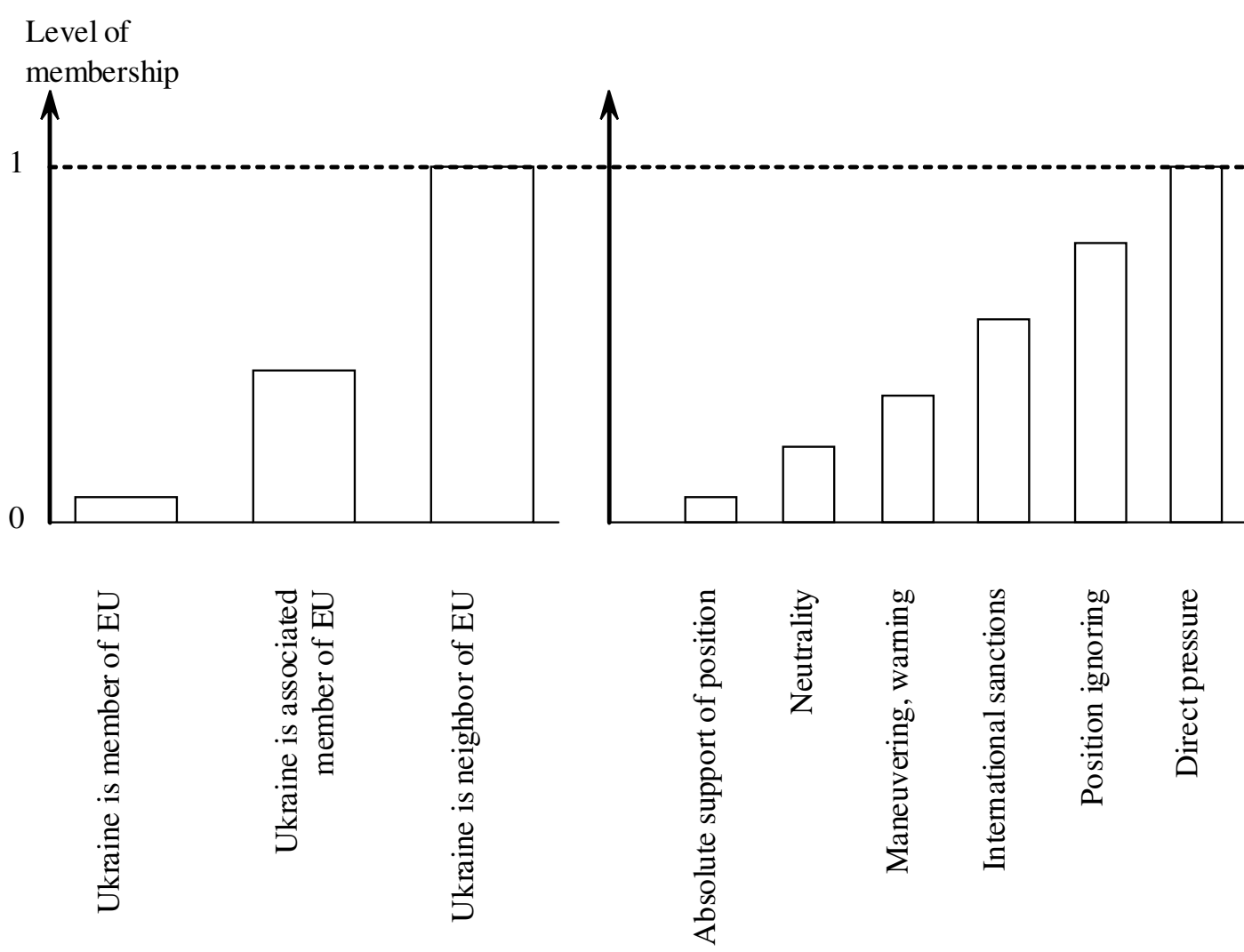

Figure 4 - Calculation of Contradictions levels

Assignment variant 2. The model uses this variant for "compound" problems: when several similar problems can be generalized to one problem for size decrease of model. As example, it is problem of trade relations. Trade relations often contain many different problems. There is no necessity to consider each problem. In such generalized problems it is difficult to formulate decision variants. Therefore the user formulates gradations set as contradictions degrees. In this case expert straight must determine the contradictions level. Figure 4 on the right demonstrates this assignment variant. In corresponding top the user equates to one the membership of selected gradation. This gradation corresponds to contradictions level between preferences of impact-addressee and preferences in information message.

\section{Calculation of coincidence levels of preferences.}

The model fulfils the calculation in the tops group "Problem 1 - Problem N" for contexts out of the tops group "SG*". In each top the user formalizes the preferences of each social group. These preferences reflect the views of social groups concerning decision variants of corresponding problem. The preferences of social groups can be determined on the basis of public-opinion polls. The model fulfils the calculation analogously to calculation of contradictions levels. However the user must formulate the fuzzy measures with reverse sense. 
The user must assign the desirability of decision variants for homogeneous problems and he must assign the coincidence level for compound problems. As integration result the model calculates the coincidence level of preferences.

\section{Calculation of familiarization level.}

The model fulfils the calculation in the top "Mass-media" for contexts out of the tops group "SG". In the top "Mass-media" the user assigns the gradations set which correspond to various mass-media. On this set the user assigns the fuzzy measure of mass-media popularity in context of each social group. The mass-media popularity in social groups can be determined on the basis of public-opinion polls. The model formalizes the publication of information messages in the form of membership on mass-media set. If the mass-media has published a message, the user equates to one the membership in corresponding gradation. The model integrates the membership along mass-media popularity measure. As integration result the model calculates the familiarization level of each social group with all messages in all mass-media.

Step 2. The estimations generalisation along all problems.

In the tops group "SG*" and "IA" the model fulfils the calculations of following estimations:

- composite level of preferences contradictions in information messages with preferences of the impact-addressee concerning all problems;

- composite level of preferences coincidence in information messages with preferences of social groups concerning all problems.

\section{Calculating of composite level of preferences contradictions.}

The model fulfils the calculation of this estimation in the top "IA" for contexts out of the tops group "SG". In the top "IA" the user assigns identical fuzzy measures for each context. These measures reflect the problems importance from view-point of impact-addressee. The model forms the membership from contradictions levels for each problem (see Step 1). The model integrates the contradictions levels along problems importance measure and calculates the composite level of preferences contradictions.

\section{Calculating of composite level of preferences coincidence.}

The model fulfils the calculation of this estimation in all tops out of the tops group "SG*" for contexts out of the tops group "SG**". In the each top out of the tops group "SG*" the user assigns the fuzzy measure of problems importance from view-point of appropriate social group. This measure can be determined on the basis of public-opinion poll. The model forms the membership from coincidence levels of preferences 
concerning each problem (see Step 1). The model integrates the coincidence levels of preferences along problems importance measure and calculates the composite level of preferences coincidence.

Step 3. The calculating of possibilities of information impact on each social group.

The model fulfils the calculations in the tops group "SG". In each top the user assigns the sub additive fuzzy measure on the set of entrance estimations. Such sub additive measure provides fulfilling of logic operation "And" at the time of integration. The model uses as entrance estimations:

- familiarization level of social group with messages in mass-media (see Step 1);

- composite level of preferences contradictions in information messages with preferences of the impact-addressee concerning all problems (see Step 2).

The model integrates these entrance estimations according to logic "And" and calculates the possibilities of information impact on each social group.

Step 4. The calculating of relations tension between the impact-addressee and each social group.

The model fulfils the calculations in the tops group "SG**". In each top of this group the user assigns also the subadditive fuzzy measure on the set of entrance estimations. The model uses as entrance estimations:

- composite level of preferences coincidence in information messages with preferences of social group concerning all problems (see Step 2);

- possibility of information impact on social group (see Step 3).

The model integrates these entrance estimations according to logic "And" and calculates the relations tension between impact-addressee and each social group.

Step 5. The estimations generalisation along all social groups.

The model fulfils the calculations in the tops "Composite possibility of information impact" and "Composite relations tension". In these tops the user assigns the identical fuzzy measures which reflect the importance (influence) of social groups in a society. The measures can be determined on the basis of data about structure of a society. Entrance estimations correspond to estimations which the model has calculated at fulfilling Step 3 and Step 4. The model integrates the entrance estimations along importance measure of social groups and calculates:

- composite possibility of information impact on all social groups;

- composite relations tension between the impact-addressee and all social groups. 
We use first estimation for fact determination of information impact, and we use second estimation for damage evaluation from information impact.

\section{MATHEMATICAL MODEL}

Let's denote as: $V=\left\{v_{l}, l=\overline{1, L}\right\}$ - the set of socially important problems; $W^{l}=\left\{w_{i}^{l}, i=\overline{1, I^{l}}\right\}$ - the set of problems decision variants; $S=\left\{s_{j}, j=\overline{1, J}\right\}$ - the set of social groups; $B=\left\{b_{k}, k=\overline{1, K}\right\}$ - the set of mass-media.

In first tops of model the user assigns the family of fuzzy measures:

fuzzy measure which formalizes unacceptability (undesirability) of problem decision variant from the viewpoint of the impact-addressee: $\varphi_{W^{l}}\left(\bullet \mid v_{l}\right): 2^{W^{l} \times V_{l}} \rightarrow[0,1]$;

fuzzy measure which formalizes desirability of problem decision variant from view-point of social group $s_{j}$ : $v_{l}: g_{W^{l}}\left(\bullet \mid v_{l}, s_{j}\right): 2^{W^{l} \times S \times V} \rightarrow[0,1]$

fuzzy measure which formalizes popularity of mass-media $b_{k}$ in social group $j: \eta_{B}\left(\bullet \mid s_{j}\right): 2^{B \times S} \rightarrow[0,1]$.

The steps in this section correspond to steps which we have described in the section "Structure of model".

Step 1. The analysis of information messages in mass-media.

Let's assume that mass-media has published one message. The user reads this message and determines the problem and the variant of its decision which are offered in the message. Therefore the message can be formalized by membership on set of problem decision variants: $\varepsilon_{v_{l}}^{b_{k}}\left(w_{i}^{l}\right): W^{l} \rightarrow[0,1]$. Then integral calculates the contradictions level of impact-addressee preferences with the preferences in the message:

$$
f_{1}\left(v_{l}, b_{k}\right)=\int_{W^{l}} \varepsilon_{v_{l}}^{b_{k}}\left(w_{i}^{l}\right) \circ \varphi_{W^{l}}\left(\bullet \mid v_{l}\right) .
$$

The symbol "f" denotes the fuzzy integral Sugeno (1972).

The following integral calculates the coincidence level of social group preferences with preferences in the message:

$$
f_{2}\left(v_{l}, s_{j}, b_{k}\right)=\int_{W^{l}} \varepsilon_{v_{l}}^{b_{k}}\left(w_{i}^{l}\right) \circ g_{W^{l}}\left(\bullet \mid v_{l}, s_{j}\right) .
$$

The following integral calculates the familiarization level of social group with message content: 
$\eta_{B}\left(b_{k} \mid s_{j}\right)=\int \mu^{k}\left(b_{v}\right) \circ \eta_{B}\left(\bullet \mid s_{j}\right)$,

$\mu^{k}\left(b_{v}\right)=\left\{\begin{array}{l}1, k=v \\ 0, k \neq v, \quad v=\overline{1, k}\end{array},(4)\right.$

where $\mu^{k}\left(b_{v}\right) \in\{0,1\}$ is membership which formalizes the publication fact of information message in massmedia $b_{k}$.

Step 2. The estimations generalisation along all problems.

Let's denote as:

$d_{V}(\bullet)$ - the measure of problems importance from view-point of impact-addressee;

$\gamma_{V}\left(\bullet \mid s_{j}\right): 2^{V \times S} \rightarrow[0,1]$ - the measure of problems importance from view-point of social group j.

The following integral calculates the composite level of preferences coincidence in information message of mass-media $b_{k}$ with the preferences of social group $s_{j}$ concerning all problems:

$f_{3}\left(s_{j}, b_{k}\right)=\int_{V} f_{2}\left(v_{l}, s_{j}, b_{k}\right) \circ \gamma_{V}\left(\bullet \mid s_{j}\right)$.

The following integral calculates the composite level of preferences contradictions in information message of mass-media $b_{k}$ with the preferences of the impact-addressee concerning all problems:

$f_{4}\left(b_{k}\right)=\int_{V} f_{1}\left(v_{l}, b_{k}\right) \circ d_{V}(\bullet)$.

Step 3. The calculating of information impact possibilities on each social group.

The model calculates the possibility of information impact as fuzzy integral of membership of fuzzy set $X^{1}=\left\{x_{1}^{1} / f_{4}\left(b_{k}\right) ; x_{2}^{1} / \eta_{B}\left(b_{k} \mid s_{j}\right)\right\}$ along fuzzy measure $\operatorname{Bell}_{X^{1}}(\bullet)$ :

$f_{5}\left(s_{j}, b_{k}\right)=\int_{X^{1}} t\left(x^{1}\right) \circ \operatorname{Bell}_{X^{1}}(\bullet)$,

where $t\left(x^{1}\right)$ is membership which the model has formed from calculation results according to formulas (3) and (5).

The fuzzy measure $\operatorname{Bell}_{X^{1}}(\bullet)$ provides fulfilling of logic operation "And".

Step 4. The calculating of relations tension between the impact-addressee and each social group. 
The model calculates the relations tension as fuzzy integral of fuzzy set membership $X^{2}=\left\{x_{1}^{2} / f_{3}\left(s_{j}, b_{k}\right) ; x_{2}^{2} / f_{5}\left(s_{j}, b_{k}\right)\right\}$ along fuzzy measure $\operatorname{Bell}_{X^{2}}(\bullet)$ :

$$
f_{6}\left(s_{j}, b_{k}\right)=\int_{X^{2}} \rho\left(x^{2}\right) \circ \text { Bell }_{X^{2}}(\bullet),
$$

where $\rho\left(x^{2}\right)$ is membership which the model has formed of calculation results according to formulas (5) and (7).

The fuzzy measure $\operatorname{Bell}_{X^{2}}(\bullet)$ also provides fulfilling of logic operation "And".

Step 5. The estimations generalisation along all social groups.

The model calculates the composite relations tension between the impact-addressee and all social groups as:

$$
f_{7}\left(b_{k}\right)=\int_{s} f_{6}\left(s_{j}, b_{k}\right) \circ \theta_{S}(\bullet)
$$

where $\theta_{s}(\bullet)$ is importance measure of social groups in society.

The following integral calculates the composite possibility of information impact on all social groups:

$$
f_{8}\left(b_{k}\right)=\int_{s} f_{5}\left(s_{j}, b_{k}\right) \circ \theta_{S}(\bullet) \text {. }
$$

\section{The calculating of simultaneous influence of several messages.}

The formulas (1) - (10) fulfil the calculations only for one moment of time and only for one information message. However, the mass-media simultaneously publish many messages. Besides, the influence force of messages is not constant (see figure 2) and the influence of various messages have also specific features. The importance of separate message and the confidence level to it greatly depend on the popularity of message author, the message content and other factors. Therefore, the model should fulfil two requirements:

- the model should be dynamic;

- the model should analyzes several messages which mass-media have published simultaneously.

Therefore before calculations (1) - (10) the model fulfils the generalisation of preferences in active information messages into one hypothetical preference with taking into account the following parameters:

- the importance $\left(C_{1}\right)$ of each message among other messages (the importance can be determined on the basis of content's topicality analysis ); 
- the confidence $\left(\mathrm{C}_{2}\right)$ to each message (the confidence can be determined on the basis of analysis of mass-media reputation or author reputation);

- the force of message influence at current time.

The model uses the received hypothetical preference in calculations (1) - (10). All entrance estimations of messages and parameters of model receive additional measurement (the time) for using calculations (1) (10) in dynamics. For example, expression (9) receives the following form:

$f_{7}\left(b_{k}, t\right)=\int_{S} f_{6}\left(s_{j}, b_{k}, t\right) \circ \theta_{S}(\bullet)$.

The model fulfils the calculation (1) - (10) some times, according to intervals number of model time. The messages number and their parameters change during of time.

Let's consider the mathematical description of several messages generalisation. Let's assume that massmedia $k$ have published the set of messages $R_{t}$ concerning the problem $v_{l}$ in fixed moment of time. We formalize each message as: $\varepsilon_{v_{l}}^{b_{k}}\left(w_{i}^{l} / t\right)$. The model calculates the preferences in generalized message as fuzzy integral:

$\varepsilon_{v_{l}}^{b_{k}}\left(w_{i}^{l}\right)==\int_{R_{1}} \varepsilon_{v_{l}}^{b_{k}}\left(w_{i}^{l} \mid t\right) \circ g_{R_{t}}(\bullet)$

where: $g_{R_{t}}(\bullet)=\left(C_{1}^{R} \otimes C_{2}^{R}\right) \otimes t_{T}^{R}(\bullet)$ is measure of life cycle of message;

$t_{T}^{R}(\bullet)$ is measure of message influence at the time (the measure has form of trapezium);

$\otimes$ is implication.

The model uses received preferences in (1) as membership in sub-integral expression.

\section{TESTING}

For algorithm testing we have created model by means of software "Expert Professional Master". We have considered the Russian-speaking national minority as impact object and the Ukrainian government as the impact-addressee. In model we have formalized preferences of Russian-speaking national minority concerning ten important state and public problems. We have set into this model the parameters of information messages which were published during 01.2005 - 02.2005 in mass-media of Autonomous republic Crimea (Ukraine). This time-period corresponds to the final stage of presidential elections in Ukraine. In total we have analyzed fifteen printed mass-media and thousand information messages. The limited size of 
MANAGEMENT RESEARCH AND PRACTICE Vol. 2 Issue 1 (2010) p: 21-38

this article does not allow showing in details all intermediate data and results. Therefore below we present only selective results of modelling.

Figure 5 demonstrates the possibility dynamics of information impact on social group "Russian-speaking national minority". This social group corresponds to the top out of tops group "SG" on figure 3 . The level 0.5 is chosen as criterion of purposeful deliberate information impact. The diagram demonstrates that information impact on the specified social group has begun after the first week of January 2005 - directly ahead of elections final stage.

Estimations of preferences contradictions out of tops which correspond to important state and public problems provide the directions revelation and purposes of information impact. Figure 6 demonstrates the estimations out of following tops: "Euroatlantic integration", "Environmental problems" and "Prestige of political power". These estimations have been calculated from view-point of impact-addressee. Diagram demonstrates that the impact has been concentrated basically on problem "Prestige of political power" and partially on problem "Euroatlantic integration". The mass-media did not concern environmental problems. Therefore it is possible to draw the conclusion that the discredit of political power was the basic purpose of information impact.

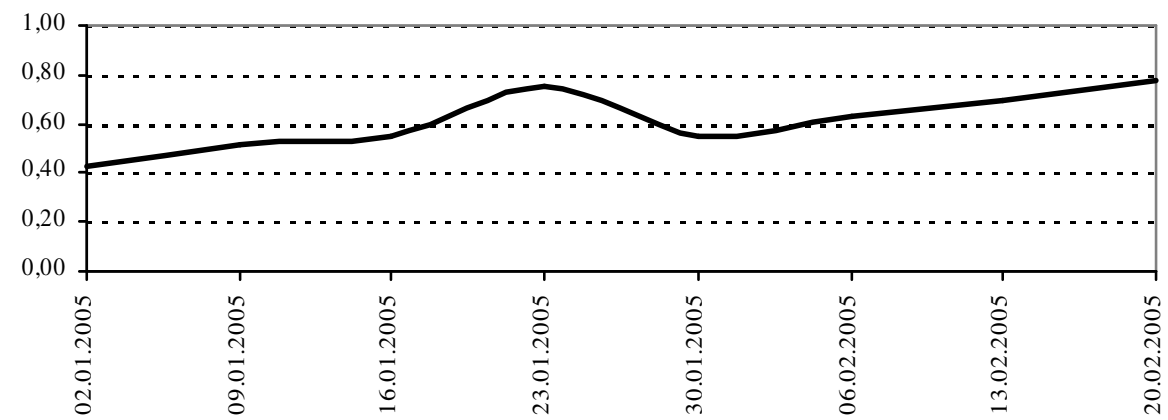

FIGURE 5 - POSSIBILITY DYNAMICS OF INFORMATION IMPACT ON SOCIAL GROUP

Figure 7 demonstrates the tension relations dynamics of the Ukrainian government with the specified social group. This tension also characterizes potential public support decrease of Ukrainian government. The tension estimations correspond to estimations for the top out of tops group "SG **" (see figure 3). The diagram shows that relations tension has not exceeded level 0.5 . It testifies that the analyzed information impact was not effective and has not reached the purpose. The Russian-speaking minority of Crimea has not supported the ideas which were declared in mass-media. 


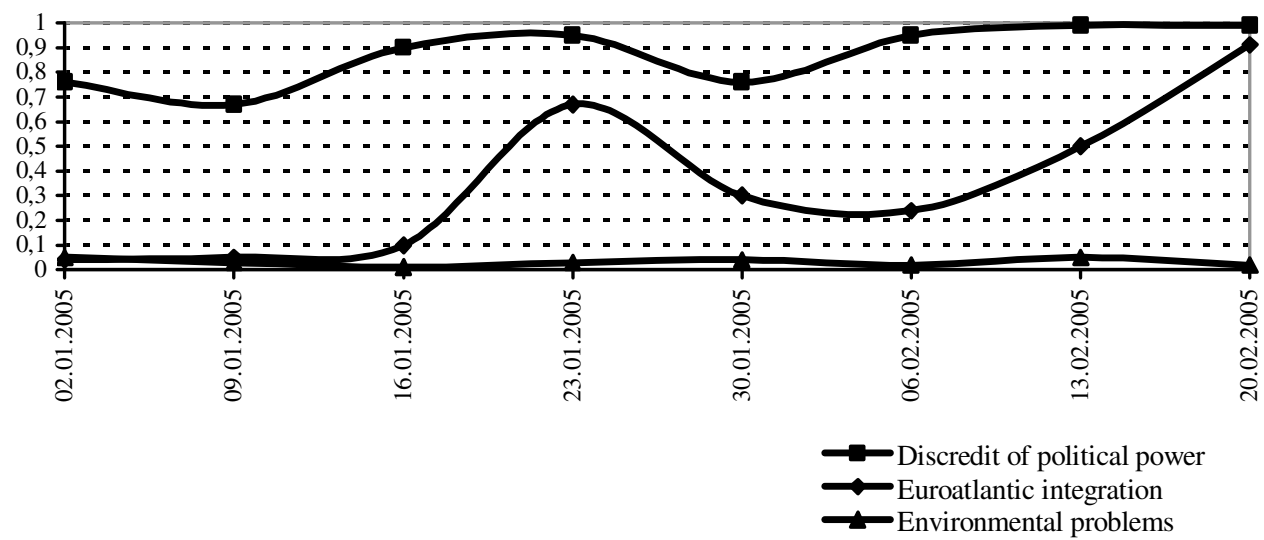

FIGURE 6 - CONTRADICTIONS DYNAMICS BETWEEN THE CONTENT OF INFORMATION MESSAGES AND THE OFFICIAL VIEW-POINT OF THE UKRAINIAN GOVERNMENT

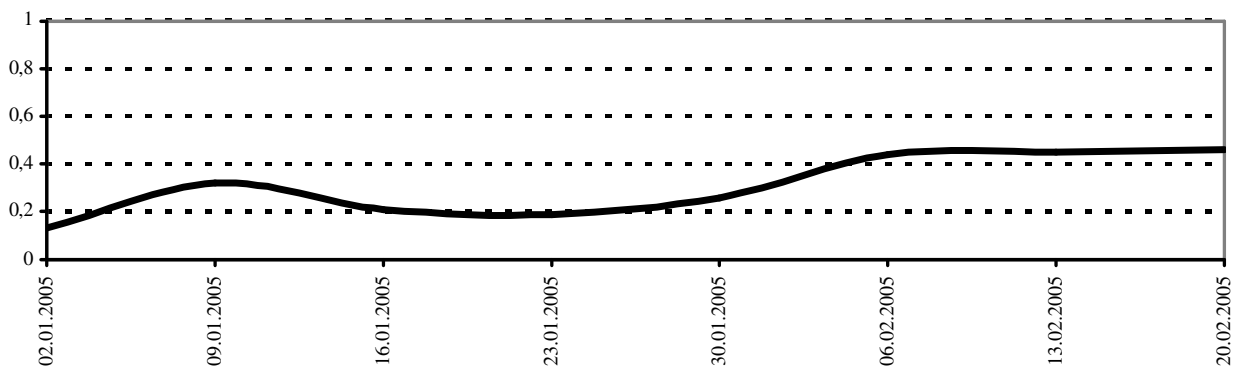

FIGURE 7 - DYNAMICS OF RELATIONS TENSION

\section{CONCLUSIONS}

Thus, the presented model allows revealing information impact and also evaluating potential damage to impact-addressee. The model uses results of polls for adjustment. The model facilitates analysts' activity concerning revelation of information impacts and can be used in real time. By means of this model the analysts' can determine the impact purpose and the impact objects. They also can evaluate the potential tension which can arise in a society as result of impact. The model can be used as analytical basis for the centres of public opinion studying and the monitoring of information space during elections and in everyday life. The model also can be used for facts determination of unfair competition, when corporations involve a public opinion into own competitive activity and fulfil the information impacts harmful to society.

\section{REFERENCES}

Asfaw, M. (2006). Analysis of socio-personal factors affecting the adaptation and Use of Information and communication technologies (ICTS) in Ethiopia. AMDS 2006 Proceedings, Dallas, TX, USA, pp. 12-21.

Cohen, J., Tsfati, Y. and Sheafer, T. (2008). The Influence of Presumed Media Influence in Politics: Do Politicians' Perceptions of Media Power Matter? Public Opinion Quarterly 72(2), pp. 331-344. 
Bocharnikov V., Sveshnikov S., Voznyak S. and Yuzefovich V.

MANAGEMENT RESEARCH AND PRACTICE Vol. 2 Issue 1 (2010) p: 21-38

Berinsky, A. J. (2006). Assuming the Costs of War. Events, Elites and American Public Support for Military Conflict. Working Paper, MIT.

Gartner, S. S. (2008). The Multiple Effects of Casualties on Public Support for War: An Experimental Approach. American Political Science Review 102, pp. 95-106.

Jajko, W. (2002). A Critical Commentary on the Department of Defense Authorities for Information Operations. Comparative Strategy 21, pp. 107 - 114.

Maier, J. (2008). Shifting Europe's Boundaries: Mass Media, Public Opinion and the Enlargement of the EU. European Union Politics, Vol. 9, No. 2, pp. 243-267.

Koster, M., Lindelauf, R., Lindner, I. and Owen, G. (2008). Mass-mobilization with noisy conditional beliefs. Mathematical Social Sciences 55, pp. 55-77.

Ladd, J. McD. (2007). Predispositions and Public Support for the President during the War on Terrorism. Public Opinion Quarterly 71.4, pp. 511-538.

Lindley, D. (2004). Untapped power? The status of UN information operations. International Peacekeeping 11 , pp. $608-624$.

Lohmann, S. (1993). A signaling model of informative and manipulative political action. American Political Science Review, 87, pp. 319-333.

Lonsdale, D. (2004). The Nature of War in the Information Age: Clausewitzian Future. Taylor \& Francis, New York.

Survey by the public opinion foundation, Retrieved March 12, 2008, from http://bd.fom.ru/report/map/du080301

Schofield, N., Cataife, G. (2006). A Model of Political Competition with Activists applied to the elections of 1989 and 1995 in Argentina. Washington University in Saint Louis, USA.

Sugeno, M. (1972). Fuzzy measure and fuzzy integral. Trans. SICE, 8, №2, 95-102. 